\title{
Note upon an Association between Spider-Crab and Sea-Anemone.
}

By

David Landsborough Thomson, M.A.

IT was observed during the summer of 1920 that specimens of the Longlegged Spider-crab, Stenorhynchus phalangium Penn., which happened to be in the crowded tanks of the Roscoff Laboratory, were always to be found in the neighbourhood of specimens of Anemonia sulcata Penn. (Anthea cereus Ellis). That this was not merely accidental was shown when crabs, removed to a distance of over three feet, returned time after time to an Anemonia, passing on the way anemones of various species, as well as all manner of objects which might conceivably afford shelter. Of fifteen healthy crabs of this species observed during the past three summers, every one showed this tendency in greater or less degree. At least two of these crabs were found clinging to anemones of this species on the shore, between tide marks; but the subsequent behaviour of crabs dredged from deeper water was in no way different.

Usually the crab takes up its position close to the column of the anemone, so as to be more or less concealed by the tentacles, only the rostrum and the first pair of walking legs being visible from above, whilst the legs of the fourth pair may reach backwards to grasp the anemone. But at times, and especially when disturbed, the crab climbs backwards right on to the crown of the anemone; and one specimen, a female bearing eggs, repeatedly worked its way right under the base of the anemone, so that only the tip of the rostrum and the limbs could be seen. The anemone makes no attempt to seize the crab, but if the crab dies its body is soon lifted up and devoured. It is clear that the crab must be well protected by the anemone, which does not retract its tentacles when disturbed. At night, when the tentacles of Anemonia usually hang limp and inactive, the crab often ventures out from its sheltered position.

If a scrap of flesh be dropped into a basin containing an Anemonia and a Stenorhynchus, the crab soon becomes aware of it, and begins to search energetically. As soon as the morsel of food is found, it is dragged back into the friendly shelter of the anemone; but in an instant one of the restless tentacles has discovered it, and it is snatched from the crab's uncertain grasp and swallowed by the anemone, while the defrauded 
owner searches the neighbourhood with a comical suggestion of bewilderment. A day or so later the undigested remains are ejected by the anemone in the form of a white film, which soon swarms with algæ and infusorians. Once again the crab begins to search, but it may be a considerable time before it finds and devours these remains. It may frequently be observed, when the crab is in its usual position, that a single tentacle of the anemone hangs loosely over the rostrum and in front of the mouth. The benefit to the anemone is thus no less plain than the benefit to the crab, in this quaint partnership, which may, perhaps, be regarded as an early stage in the establishment of a true commensalism. 